\section{Significado da Química no Estudo das Plantas}

\author{
MARIA E. WEBB*
}

A compreensão da importância de relacionar os efeitos da componente quimica dos vegetais no Homem com a morfologia destes teve, possivelmente os seus inícios com 0 advento da Agricultura. A necessidade de poder distinguir as plantas comestiveis das não comestiveis devido, por exemplo, à sua toxicidade, levou o Homem a agrupá-las, de forma a poder comunicar a sua experiência a outros membros da sociedade. De igual modo, a utilização das plantas para fins medicinais e na preparação de cosméticos veio, a pouco e pouco, aumentando o número não só de grupos como também 0 de elementos dentro de cada grupo. Poucas destas designaçōes chegaram até aos nossos dias podendo, no entanto ser ainda encontradas naquilo que se designa por taxonomias populares. Embora as correlações entre caracteres químicos e morfológicos sejam muito anteriores, Hipócrates (460-355 a.C.) é considerado como tendo sido o primeiro a efectuar uma lista de plantas de acordo com os seus usos medicinais e alimentares.

Várias compilações deste género foram surgindo, existindo em cada uma delas em menor ou maior grau, a preocupação de agrupar as plantas de acordo com as utilizaçōes que thes eram dadas. Neste contexto é curioso notar que a aplicação das propriedades químicas das plantas em medicina levou Petiver (1699) a descrever as semelhanças morfológicas apresentadas por plantas com "virtudes curativas" idênticas.

0 trabalho de Helen Abbott (1886) sobre o significado taxonómico da distribuição de saponinas sugerindo, ao mesmo tempo, a correlação entre constituintes químicos e vias evolutivas em plantas, marcou o inicio da quimiossistemática.

0 estudo dos compostos químicos sintetizados e acumulados pelas plantas tem metodologias de abordagem diferen- dado que as vias biossintéticas das plantas são diversificadas, ou seja, nem todos os taxa sintetizam e acumulam toda a variedade de compostos encontrados nos vegetais.

A selecção de um determinado grupo de plantas a fim de se proceder à análise de compostos químicos é considerada como o primeiro passo na aproximação quimiossistemática. A escolha recai, em geral e por razões de ordem prática, sobre uma determinada categoria taxonómica, como por exemplo, uma ordem, uma família ou um género. Mesmo assim é, por vezes, dificil obterem-se todas as subcategorias, especialmente quando 0 taxon seleccionado engloba um número razoável de subcategorias. De uma forma mais concreta, consideremos que a categoria taxonómica seleccionada para o nosso estudo é constituída por uma determinada familia. Todos os subgrupos devem ser obtidos para análise. Assim, seria necessário termos acesso a espécies pertencendo a cada um dos géneros que constituem as várias tribos, sendo estas representativas de cada subfamília. No caso de uma determinada espécie, várias populações originárias de habitats distintos e áreas geográficas diferentes devem ser colhidas para análise. No caso da aproximação quimiossistemática, dado que 0 grupo de plantas é seleccionado em primeiro lugar, a classe ou classes de compostos a estudar encontra-se, pelo motivo já anteriormente referido, dependente do grupo vegetal seleccionado.

Tanto em relação à aproximação fitoquímica como em relação à aproximaçāo quimiossistemática, a consulta prévia da matéria publicada sobre o tema a estudar tem como principais vantagens: (i) Auxiliar na selecção de métodos de análise, muito em especial técnicas de extracção e separação (ii) no caso de 0 volume de informação sobre este taxon e/ou classe de compostos ser já considerável, auxiliar a uma criteriosa selecção dos taxa e/ou compostos químicos ou fazer reflectir sobre a necessidade da realização do estudo.

Outro aspecto importante refere-se à quantidade de material vegetal requerido pelas técnicas de análise escolhidas.

Em geral, a disponibilidade de material

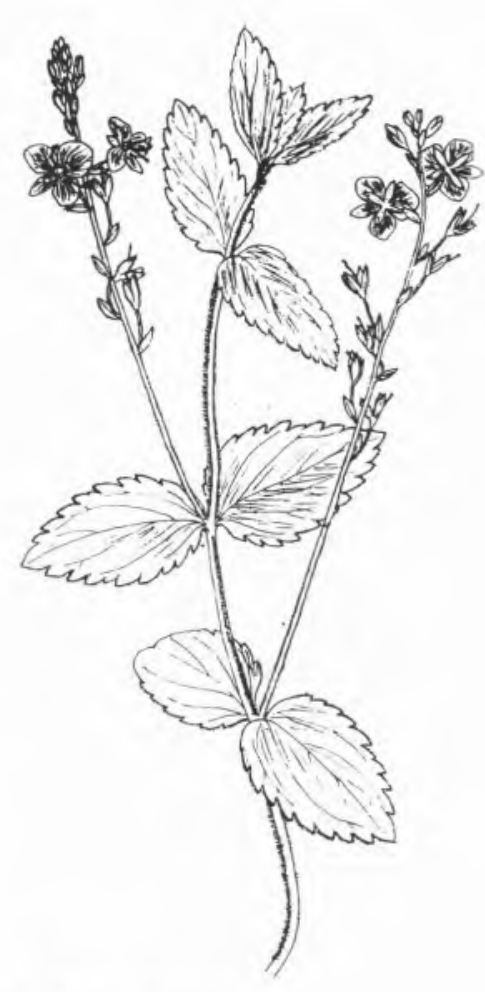

Fig. 1 - Veronica chamaedris L.

vegetal não é grande e deve ter-se em atenção que só é possivel efectuar comparaçōes, fundamentais em quimiossistemática, quando as mesmas técnicas, 0 mesmo orgão da planta e a mesma quantidade de material vegetal são utilizados.

Embora os vegetais exibam um vasto leque de constituintes quimicos, tem-se verificado que os produtos do metabolismo secundário, preenchem os requesitos necessários à sua utilização em Quimiossistemática. Na verdade, muitos destes requerem técnicas relativamente pouco sofisticadas, encontramse presentes em quantidades detectáveis, são, na generalidade, estáveis e podem ainda ser utilizados como marcadores quimiossistemáticos. Este tipo de metabolitos inclui uma multiplicidade de compostos de baixo peso molecular, tais como terpenóides, flavonóides e amino ácidos não-proteicos para mencionar apenas alguns, talvez os mais frequentemente detectados como sendo de ocorrência natural. Para além destes torna-se ainda importante mencionar a importância que compostos induzidos têm apresentado em Quimiossistemática. Abordaremos assim 0 significado que as fitoale$\operatorname{xinas}^{(*)}$ têm na delimitação de géneros taxonomicamente dificeis.

Os padrões de distribuição destes mesmos compostos em vários taxa são elucidativos do seu significado taxonómico, como veremos a seguir.

0 termo terpenóide abrange uma vasta gama de substâncias de origem vegetal e é utilizado no sentido de indicar que todas essas substâncias tem uma origem biossintética comum. Estes compostos baseiam-se na molécula de isopreno, sendo o seu esqueleto de carbono 
construido a partir da união de duas ou mais destas unidades em $\mathrm{C}_{5}$. Os terpenóides são então classificados de acordo com o número das unidades de isopreno. Muitos exemplos ilustrando a importância taxonómica destes compostos, que são detectados tanto como componentes de óleos essenciais como sob a forma de pigmentos - os carotenóides - poderiam ser mencionados.

Selecccionámos no entanto, 0 estudo realizado em espécies de Veronica (Fig. 1) e outras de géneros relacionados com este (Hebe, Parahehebe, Veronicastrum e Paedorata), utilizando os compostos monoterpénicos designados iridóides. A estrutura destes compostos baseia-se num sistema de anel de ciclopentanodihidropirano (Fig. 2), reconhecendo-se cinco grupos. Para a compreensão deste exemplo, é suficiente referir que os iridóides "propriamente ditos" ocorrem principalmente sob a forma glucosidica, contendo um grupo B-D-glucosil na posição C-1.

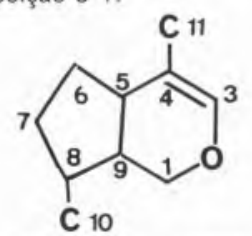

Fig. 2 - Sistema de anel de ciclopentanodihidropirano.

A análise cromatográfica destes compostos conjuntamente com a de flavonóides (ver adiante) sintetizados e acumulados pelos taxa em questão serviu de auxílio na delimitação do género Veronica. 0 género engloba um elevado número de espécies (cerca de 150, de acordo com Römpp, 1928) e assim a relação existente entre estas e as de géneros afins torna-se importante do ponto de vista sistemático. A Tabela I refere as diferenças detectadas a nivel dos padrões químicos (iridóides e flavonóides) entre Veronica $s$. str. e géneros relacionados com este.

Embora as diferenças detectadas ao nivel dos caracteres químicos confiram uma base de apoio quanto à separação de Paedorata, Veronicastrum, Hebe, Parahebe e Pymea de Veronica, a distinção entre Hebe, Parahebe e Pygmea com base nos resultados fornecidos pelos iridóides é difícil. Os padrões químicos detectados forneceram caracteres úteis que permitiram compreender as relações existentes no seio de Veronica s. 1. .Os iridóides surgem neste exemplo como compostos elucidativos das relações existentes ao nivel genérico e também no seio de Veronica s. str.; acima da categoria especifica permitem 0 estabelecimento de grupos ao nivel da secção e subsecção.

Não só em membros da família Scropholariceae a presença de iridóides foi detectada; na família Rubiaceae (à qual pertence o cafeeiro), por exemplo, asperolósido é um dos iridóides frequentemente detectados em alguns dos seus membros. É interessante referir que estes compostos de gosto amargo são os principais responsáveis pelo escurecimento de várias éspecies durante 0 processo de herborização, incluindo-se neste grupo determinadas plantas parasitas ou semi-parasitas pertencentes à familia Scropholariaceae.

A côr escura surge por hidrólise da forma glicosidica e posterior polimerização dos aglicões que, apesar do que se poderia suspeitar, são praticamente desprovidos de actividade antimicrobiana. Na verdade são formas não-glucosídicas, como por exemplo plumericina, genipina ou ácido genípico, que mostram uma maior actividade antimicrobiana. 0 número de plantas contendo iridóides e com utilização em medicina é relativamente grande sabendo-se que estes compostos podem ter, para além de actividade antimicrobiana, efeitos sedativo, laxante, diurético, antileucémico e hipotensor.

Englobados na vasta classe de compostos fenólicos encontra-se um grupo de constituintes vegetais que, pela sua frequência, abundância e variedade estrutural tem sido muito da preferência dos quimiossistematas - os compostos flavónicos ou flavonóides, 0 termo aplica-se a um número já muito elevado de estruturas conhecidas. Estas baseiam-se num núcleo com 15 carbonos, constituído por dois anéis benzénicos ( 0 anel $\mathrm{A}$ e 0 anel B) ligados por um anel pirânico (0 anel C) (Fig. 3). Diferentes niveis de oxidação da estrutura central em $\mathrm{C}_{3}$ permitem a divisão deste grupo de compostos de ocorrência natural em vários subgrupos, como por exemplo as antocianidinas os flavonóis, as flavonas, as flavano-

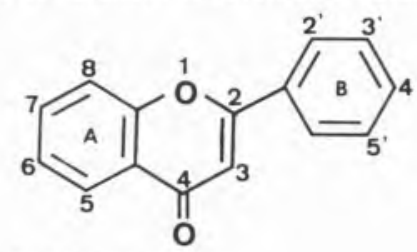

Fig. 3 - Núcleo flavónico.
Tabela I - Caracteres Quimicos que distinguem os géneros Paedorata. Veronicastrum, Hebe, Parahebe e Pygmea de Veronica s.str.

\begin{tabular}{|c|c|c|}
\hline \multirow{2}{*}{ Géneros } & \multicolumn{2}{|c|}{ Caracteres Quimicos } \\
\hline & Iridóides & Flavonóides \\
\hline Paedorata & $\begin{array}{l}\text { - Esters de catalpol baseados } \\
\text { em derivados do ácido benzóico } \\
\text { - Ausência ou baixa concentraçáo } \\
\text { de protocatequilcatalpol. }\end{array}$ & $\begin{array}{l}\text { - Presença de 6-hidroxiflavonas } \\
\text { metiladas }\end{array}$ \\
\hline Veronicastrum & $\begin{array}{l}\text { - Ausência de catalpol e } \\
\text { esters de catalpol. }\end{array}$ & - Presençą de flavonovas metiladas \\
\hline Hebe & $\begin{array}{l}\text { - Esters de aucubina } \\
\text { - Esters de catalipol baseados } \\
\text { em derivados do ácido cinàmico } \\
\text { dominando sobre os derivados do } \\
\text { ácido benzóico. }\end{array}$ & - \\
\hline Parahebe & $\begin{array}{l}\text { - Esters de aucubina } \\
\text { - Esters de catalpol baseados } \\
\text { em derivados do ácido cinâmico } \\
\text { dominando sobre os derivados do } \\
\text { ácido benzoico }\end{array}$ & $\begin{array}{l}\text { - Ausência de flavonas metiladas } \\
\text { - Maior variedade de padrỏes de } \\
\text { glicosilação. }\end{array}$ \\
\hline Pygmea & - Esters de aucubina & - Presença de 6-hidroxiflavonas \\
\hline
\end{tabular}

(Adaptado de Grayer-Barkmeijeri 1973 e 1978)

nas, os biflavonilos e as proantocianiclidinas. As isoflavonas e as auronas por exemplo são diferentes dos compostos acima mencionados, devido a uma modificação biossintética da estrutura básica do 2-fenilbenzopirano. Alguns destes subgrupos têm uma distribuição mais vasta do que outros. Assim, enquanto antocianidinas, flavonóis e flavonas se encontram numa grande variedade de grupos de plantas, os restantes compostos apresentam uma distribuição mais restrita. Por definição os flavonóis têm um grupo hidroxil ligado à posição-3, enquanto que as flavonas não apresentam este grupo. A variação estrutural encontrada neste tipo de compostos relaciona-se essencialmente com os padrões de hidroxilação, metilação, glicosilação, acilação e sulfonação.

Embora as formas livres (os aglicões) possam ser encontradas nas plantas, tanto flavonóis como flavonas são em geral detectados sob a forma glicosidica. Esta forma é mais hidrosolúvel e mais estável no interior da planta, acumulando-se geralmente no vacúolo.

A glicosilação pode ocorrer mais frequentemente em algumas posições da estrutura básica do que noutras. Dado que as flavonas não têm um grupo hidroxil na posição -3, os glicósidos ligam-se em geral à posição -7 , embora outras posições, como a 5- e 4 - possam também apresentar-se glicosiladas.

Nestas formas conjugadas, os glicósidos encontram-se ligados ao núcleo flavónico por uma ligação glicosídica. No entanto, estes podem ligar-se através de uma ligação carbono-carbono, a um ou 
mais dos átomos de carbono do núcleo flavónico básico. A glicosilação de outras posiçōes pode, de igual modo, ocorrer.

Após esta breve introdução relativa às caracteristicas básicas das estruturas quimicas destes compostos vejamos de que forma eles têm sido utilizados em estudos quimiossistemáticos. Como já referimos, os flavonóides ocorrem numa grande variedade de plantas $e$ as intensivas e extensivas análises até hoje realizadas indicam que estes compostos têm uma distribuiçao quase universal nas Angiospérmicas. Vejamos, através de alguns exemplos, o tipo de informação que é possivel obter.

A utilidade do(s) caracter(es) provenientes(s) da análise de compostos flavónicos pode depender do nivel taxonómico; assim, na família Araceae (na qual se encontra incluido 0 jarro de jardim), embora o perfil flavónico mais ou menos uniforme apresentado pelos taxa analisados não permita uma distinção entre as várias subfamilias, obtiveram-se padrões taxonómicos significativos ao nível da tribo. Ao nivel da subtribo, foi possivel distinguir a subtribo Arinae. com base na homologia dos flavonóides apresentada pela maioria dos seus membros (Williams et al, 1981).

Ao nivel genérico cada espécie apresenta o seu padrão flavónico, geralmente como diferentes formas glicosídicas do ou dos aglicões detectados. Este padrāo específico pode ser de utilidade na abordagem de diferentes tipos de informação. Das análises levadas a efeito em diferentes espécies de Eleusine (Gramineae) foi possivel (i) confirmar quimicamente a posição isolada de Eleusine compressa dentro do género, (ii) mostrar a estreita relação existente entre caracteres morfológicos e padrões flavónicos no que se refere às restantes espécies e (iii) tendo-se ainda confirmado a origem de $E$. coracana ssp. coracana a partir de E. coracana ssp. africana (Hilu et al., 1978).

Na verdade, os padrões flavónicos podem ser utilizados na detecção de híbridos ou na identificação da geração parental desses híbridos. Demonstrou-se existentes. Estes padrões flavónicos aditivos foram detectados em vários estunicos herdados são geralmente aditivos; deste modo a comparação do padrão apresentado pelo híbrido com 0 apresentado por cada um dos progenitores pode dar indicações úteis quanto às relações dos, como os levados a efeito sobre Glycine, por exemplo (Vaughan e Hymowitz, 1984).

Os flavonóides considerados durante muitos anos como compostos supérfluos do metabolismo vegetal, tornaramse de grande importância na compreensão das interacções existentes entre as plantas e os diversos organismos que fazem parte do seu habitat. Grande parte do conhecimento actual deriva das correlaçōes existentes entre dados provenientes de análises químicas e a biologia dos organismos interactuantes.

Em relação a outro tipo de compostos inicialmente abordado, os amino ácidos, podemos dizer que são caracterizados pela presença de pelo menos um grupo amina e um grupo carboxil nas suas estruturas.

Do ponto de vista bioquímico estes componentes nitrogenados dos vegetais encontram-se convenientemente agrupados em:

a) Amino ácidos proteicos, incluindo os vinte constituintes das proteinas.

b) Amino ácidos não-proteicos que ocorrem no estado livre ou como produtos de condensação, incluindo não só amino ácidos mas também as suas amidas e imino ácidos.

Os amino ácidos não-proteicos ocorrem numa grande variedade de organismos, incluindo na alga vermelha Condria coerulescens; no entanto, é nas plantas superiores que vamos encontrar uma maior variedade deste tipo de com. postos. Estudos levados a efeito sobre a distribuição de amino ácidos não-proteicos demonstraram que estes podem ser utilizados na confirmação ou definição de grupos de plantas, a diferentes niveis taxonómicos.

Tomemos como exemplo o trabatho desenvolvido em espécies dos géneros Vicia (Fig. 4) (Webb, 1989) e Lathyrus (família Leguminosae, subfamília

Fig. 4 - Vicia sativa L.

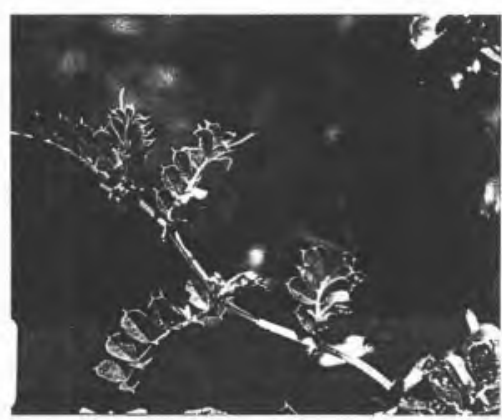

Papilionoideae, tribo Vicieae) (Bell e Tirimanna, 1965), aos quais pertencem a faveira e a ervilha de cheiros respectivamente. Vários membros destes géneros apresentam semelhanças morfológicas bastante acentuadas 0 que dificulta, por vezes em extremo, a sua delimitação e identificação. Assim verificou-se que as análises efectuadas num número representativo de espécies de Lathyrus e de Vicia contribuiam para a caracterização de cada um dos géneros, com base na acumulação de amino ácidos não-protei$\cos$. Observe-se que enquanto os membros do género Lathyrus acumulam compostos guanidino, em $\mathrm{C} 7$ [homoarginina, $\gamma$-hidroxihomoarginina e $\beta$-(2amino-pirimidina-4-il) alanina] ou ácido $\alpha-, \gamma$-diaminobutírico (Fig. 5-A), as espécies englobas no género Vicia sintetisam e acumulam compostos em C6 (arginina e $\gamma$-hidroxiarginina) ou canavanina (Fig. 5-B). Ao nivel infragenérico, foi ainda possivel dividir tanto Vicia como Lathyrus em grupos caracterizados pelo seu perfil em amino ácidos.

A presença do ácido $\alpha, \gamma$-diaminobutírico em algumas das espécies de Lathyrus analisadas é responsável pela grave doença do sistema nervoso designada neurolatirismo. Um outro amino ácido não-proteico e que provoca osteolatirismo, manifestado por sérias deformações ósseas foi igualmente detectado em espécies deste género. Dado que, em determinadas zonas, nomeadamente na Índia, as espécies que contêm estes compostos são utilizadas na alimentação, tanto uma forma como outra de latirismo atingem, especialmente em periodos de seca (o que equivale a fome, em muitas áreas do globo), proporçoes dramáticas. Embora o "alvo" destes produtos tóxicos do metabolismo secundário de Lathyrus, nāo seja muito provavelmente o Homem, facto é que este tem sido uma das suas principais vítimas. Dado que estes compostos são também tóxicos para outros vertebrados é possivel que a sua acumulação nas sementes de algumas destas plantas, Ihes confira uma certa protecção em relação ao ataque levado a efeito por roedores e/ou outros predadores. Um destes compostos é ainda capaz de inibir a germinação de sementes de várias espécies que não o produzem, apresentando assim efeitos alelopáticos.

Na verdade, tanto iridóides, como flavonóides, além dos amino ácidos nãoproteicos, encontram-se frequentemente ligados a funções defensivas nas plantas. Como já anteriormente referimos, estes 
A)

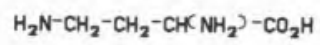

B)

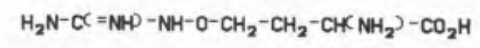

Fig. 5 A - Estrutura do amino ácido não-proteico $\alpha, \gamma$-diaminobutírico

B - Estrutura do amino ácido não-proteico canavanina.

Me $\cdot \mathrm{CH}_{2} \cdot \mathrm{CH}=\mathrm{CH} \cdot \mathrm{C}=\mathrm{C} \cdot \mathrm{CO} \cdot \mathrm{C}=\mathrm{CH}-\mathrm{CH}=\mathrm{C} \cdot \mathrm{CH}=\mathrm{CHCOOM}$

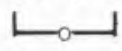

Fig. 6 - Estrutura de wyerone( $\left.{ }^{*}\right)$, uma fitoalexina poliacetilética.

(") Designação derivada do nome do colégio inglês onde foi detectada pela primeira vez (Wye College).

compostos são de ocorrência natural, ou seja, não são induzidos. 0 número de espécies testado até hoje, em relação à produção de compostos induzidos pela acção de agentes quer bióticos quer abióticos, é considerável. 0 contacto destes agentes com a superfície de uma planta saudável vai activar um sistema enzimático latente e permitir a sintese de novo de um ou mais compostos que, em princípio, irão ter um papel activo na resistência a doenças. Nem sempre 0 esforço dispendido na sintese destes compostos, designados fitoalexinas, é coroado de êxito em relação à salvaguarda dos interesses da planta, isto é, nem sempre 0 agente patogénico é vencido. Na maior parte dos casos a sua acção é retardada. No entanto, é inegável que as fitoalexinas desempenham um papel importante na resistência a doenças em espécies vegetais e em conjunto com as substâncias alelopáticas, fornecem uma perspectiva sobre as relações existentes entre plantas e entre estas e outros organismos, como fungos, bactérias ou insectos, por exemplo.

- De que forma têm estas substâncias, igualmente produtos do metabolismo secundário e distribuidos por classes de compostos químicos tão diversas como a dos poliacetilénicos, encontrando aplicação em quimiossistemática?

Do ponto de vista sistemático é significativo que o tipo de fitoalexina induzido por um determinado fungo seja específico em relação às espécies englobadas numa familia; de um modo geral cada família produz o seu próprio tipo de composto, que por sua vez apresenta uma certa relação com os constituintes, também derivados do metabolismo secundário, que sāo acumulados como produtos naturais. Assim sabe-se que os membros analizados e englobados na família Compositae (à qual pertence 0 malmequer) produzem compostos poliacetilénicos enquanto os da familia Sola- naceae (onde se encontra englobado 0 género ao qual pertence a batateira) sintetizam sesquiterpenóides.

Como excepção a esta "regra" temos de reconhecer a familia Leguminosae. Nesta familia têm sido detectados interessantes padrōes em relação aos géneros e tribos que dela fazem parte. Retomemos a análise da tribo Viciaea. Além de Vicia e de Lathyrus a tribo engloba ainda os géneros Pisum (a erviIheira), Lens (a lentilha) e Vavilovia. Este último não tem levantado problemas em relação a sua posição taxonómica e delimitação, o que já não se aplica a qualquer dos outros quatro. As análises levadas a efeito em espécies de Vicia, Lathyrus, Lens e Pisum (Ingham, 1981) vieram demonstrar a existência de uma dicotomia a nivel da produção de fitoalexinas. Assim, enquanto Vicia e Lens produzem compostos furanoacetilénicos (Fig. 6), Lathyrus e Pisum produzem compostos do grupo dos pterocarpanos (isoflavonóides) (Fig. 7).

É interessante notar que tanto os dados obtidos das análises dos amino ácidos não-proteicos como os relativos às fitoalexinas diferenciam dois géneros englobando espécies que, do ponto de vista morfológico, apresentam fortes semelhanças.

Este aflorar da quimiossistemática, um tema interessante e ainda com muito para estudar não pretende, de modo algum, ser exaustivo Esperemos que 0 interesse tenha sido despertado. Convém ter em mente que as principais atribuições de um quimiossistemata envolvem

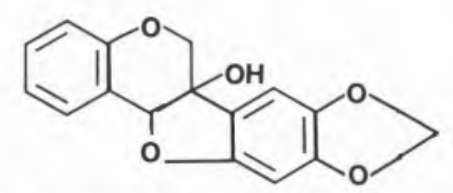

Fig. 7 - Estrutura de pisatina, um pterocarpano com actividade fungitóxica. a interpretação dos dados obtidos das análises químicas e disponibilizá-las, subsequentemente, aos taxonomistas. A revisão das classificações existentes só pode ser feita após serem considerados dados provenientes de outras disciplinas (morfologia, anatomia, citologia, etc.).

Para além da importância que 0 estudo interpretativo da distribuição de cada uma das classes de compostos acima mencionada tem em Quimiossistemática e do contributo desta disciplina para uma classificação natural, podemos ainda acrescentar a possibilidade de se encontrarem novos compostos, aumentando assim 0 número de estruturas conhecidas. Traz ainda como vantagem a existência de dados suficientes para que análises mais detalhadas sobre estrutura e actividade biológica dos compostos previamente reportados possa vir a ser feita.

-Faculdade de Ciências e Tecnologia, U.N.L.

(*) Fitoalexinas são compostos sintetizados de novo em resposta a uma tentativa de invasão dos tecidos vegetais por um agente biológico. $A$ indução feita através de um agente abiótico é também considerada como dando origem à produçāo de fitoalexinas

\section{BIBLIOGRAFIA}

H. C. De S., Abbott - Certain chemical constituents of plants considered in relation to their morents of plants considered in relation to their mor-
phology and evolution. The Botanical Gazette 11 phology and evoluti
(1866) $270-272$.

R. J. Grayer-Barkmeijer - A chemosystematicstudy of Veronica: Iridoid glucosiedes. Biochem. Syst. 1 (1973) 11-110.

R. J. Grayer-Barkmeijer - Flavonoids in Parahebe and Veronica: A chemosystematic study. Biochem. Syst, Ecol. 6 (1978) 131-137.

K. V. Hilu; J. M. J. Wet; D. De e Seigler - Flavonoid patterns and systematics of Eleusine. Biochem. Syst. Ecol. 6 (1978) 247-249.

J. L. Ingham (1981) - Phytoalexin induction and its taxonomic significance in the Leguminosae (subfamily Papilionoideae). In "Advances in Legu(subfamily Papilionoideae), In "Advances in Legu-
me Systematics" (R. M. Polhill e P. H. Raven, me Systematics" (R. M. Polhill e P. H. Raven,
eds), parte 2 pp. 599-626. Royal Botanic Gardens, Kew.

J. Petiver - Some attempt made to prove that herbs of the same make or class for the generality, have the like virtue and tendency to work the same effects. Phil. Trans. R. Soc. (Abridged) pp. same effects. Phil. Trans.
416-418. (1699) London.

H. Rompp - Die Verwandschaftsverhältnisse in der Gattung Veronica. Repert. Spec. Nov. Regn. Veg. Bei. 50 (1928) 1-171.

D. A. Vaughan, e T. Hymowitz - Leaf flavonoids of Glycine subgenus Glycine in relation to systematics. Biochem Syst, Ecol. 12. (1984)

M. E. Webb - Chemosystematic Studies in Genus Vicia (Leguminosae). Ph. D. Thesis. University of Reading. U. K. (1989)

C. A. Williams; J. B. Harborne, e S. J. Mayo. Anthocyanin pigments and leaf flavonoids in the family Araceae. Phytochemistry 20 (1981) 217 234. 